\title{
EVALUATING ENVIRONMENTAL CONSIDERATIONS WITH CHECKLIST AND DELPHI METHODS, CASE STUDY: SURAN CITY, IRAN
}

Mohamad Javad OmaraShahestan ${ }^{* 1}$, Samira OmaraShastani ${ }^{2}$

${ }^{1}$ MSc student of natural disaster management, University of Tehran, Iran.

${ }^{2}$ Student of Education Science, Islamic Azad University, Iran.

*Corresponding author email: s.omara.shahestan@gmail.com,shshestan.omara.m@ut.ac.ir

This is an open access article distributed under the Creative Commons Attribution License, which permits unrestricted use, distribution, and reproduction in any medium, provided the original work is properly cited.

\section{ARTICLE DETAILS}

\section{Article History:}

Received 1 July 2017

Accepted 2 October 2017

Available online 1 November 2017

Keywords:

\section{Evaluation studies}

Environmental monitoring,

Suran, Checklist method,

Expert opinion approach.

\section{ABSTRACT}

One of the major environmental concerns is to ensure that projects and projects are operational in accordance with the provisions and commitments contained in the report of the evaluation studies approved. In order to assess the extent to which environmental considerations are implemented, assessment reports are for reporting to supervisory organizations to ensure uniformity and procedural unity in their reporting process. The most practical methods are checklist. This study presents the evaluation process considerations environmental criteria, data collection and validation addressed and the plans and projects, including studies of environmental assessment includes the site of the elimination of waste, integrated cooking facilities, four stations, cement factory, the reservoir dam and the water pipeline transmission line by determining the scale and pollutant indicators separately for each case in the city of Suran in the south-east of Iran. Plans and projects that have actual effects on the environment of the studied area are weighted according to experts or Delphi. It can be concluded that according to the type of bricks and the type of fuel used by the factory (fuel oil), emissions such as emissions of fluorine from non-metallic minerals such as clay and compounds of nitrogen oxides and sulfur at the outlet of smoke the furnace has actual effects on the environment. Also, the slowing of the flow of water, coupled with low recharge, has increased the number of mineral particles and organic matter deposits. Finally, the status of the existing environmental monitoring program process in Iran has been studied and a new upgraded process is being proposed and proposed.

\section{INTRODUCTION}

Industrialization and the growth of economic efficiency without attention and respect to environmental protection led to the destruction of natural ecosystems, the incidence of adverse effect to health, deforestation, air pollution, damage to the ozone layer, global warming and vast alterations in climate caused Is. All of the above factors led to the introduction of new concepts for preventing environmental degradation. Major efforts have emerged in the concept of sustainable development, one of the key tools for achieving this, is the implementation of studies on the environmental impact assessment of development projects and projects [1]. These studies identify and analyze the effects of projects by reviewing the microprojects, and provide executive solutions to minimize negative impacts $[2,3]$. Assessment in developing countries as a method and tool environment to identify the possible effects of suggested projects, analysis of possible outcomes and impacts of a project on environmental elements, ensuring proper project and finally reduction strategies and the reduction of adverse effects on the environment is known [2,4]. Accordingly, the objectives of evaluation studies can be summarized as follows: Establishing a balance between the long-term goals of development and the need for the majority of people to use resources to protect the environment, maintain the quality of non-renewable resources, and operate with the highest returns and maintain cycles vital to recognize the critical problem of the environment in order to control them, define the duties of each governmental organization for environmental protection, implementation and integration of environmental criteria in planning and construction, the opinions of the public in the decision-making process, fade and Restoring environmental damage, providing healthy and active life for Maintaining the health and welfare of the community in line with preserving the quality of the environment, increasing environmental knowledge at various levels of society and decision makers, removing inconsistencies between people in the community and government organs, validating the state internationally $[2,4,5,6]$.

In this area, research on the regional and international level is carried out, which is mentioned below in some of the most important researches: Namdari et al. (2012) Environmental impacts of bricks production in Mohammad AbadGhahab, Isfahan city [7] And MohammadiSadabad (2013) have analyzed the environmental impacts of brick burning furnaces at the leading factory in the east of Bojnurd[8], and provided some solutions to improve the quality of the environment. The exact amount of air pollution from the gas stations of Ahwaz city has been investigated by Hessampour et al. (2006). The effects of pollutants on the environment have been investigated [7]. Roothean et al. (1394) have considered the harmfulness of the unconventional harvesting of the Gibson mine and the Gilan mine in the extinction of this river fish, especially whitefish [9]. Abbasi and Salari (2006) investigated the effects of damming on the fauna and flora of the area and provide solutions for arid areas, and concluded that the construction of underground dams in arid areas and the application of nanotechnology are suitable solutions to reduce the negative effects of damping. Be [10]. Environmental Protection Organization of Iran (1387) model for assessing the environmental impacts of development projects proposed [2] followed by the 1394 model systematic supervision and environmental monitoring plans and projects with a view to creating maximum trust between decision-makers and published the people.

\section{MATERIALS AND METHODS}

\subsection{Geographical and environmental situation in the research field}

The city of Apache and Suran in the south-east of Iran, with an area of 6780 square kilometers, is neighboring the east with Pakistan. Its geographic 
coordinates are 62 degrees 5 minutes east longitude and 27 degrees and 14 minutes north latitude. It has four districts (Paskouh, Suran, Hedoch and Kent) and two metropolitan centers, including Suran and Hiddoch. The total population of the city, according to the 2006 census, was 61,507 . The distance to Tehran is 1950 kilometers and its elevation is 1131 meters. The weather is warm and dry in Apples and Suran, with an average annual precipitation of $105.7 \mathrm{~mm}$. The cultivated and cultivating area is over 10,000 hectares, of which $45 \%$ is allocated to the cultivation of gardens and $55 \%$ to annual crops. The most important garden product is the date with an annual production of 21 thousand tons. The main crops are alfalfa, barley, wheat and corn. [11] For the dominant wind from north to south and the general slope of the earth, the area is from northwest to south east. One of the most important mountainous areas is the southern slope of Mount Birk. The Mashkid River is 8 kilometers east of Kuhak and leaves the country to Pakistan. The main branches of the river are the Semish, Rotak and Mashkid, where Mashkid and Rotak branches play an important role in supplying the water resources of the city of Suran.

\subsection{Method of conducting studies}

There are various methods for conducting evaluation studies that can be used based on the type of project that is linear or point-based. Analysis and evaluation methods are tools for identifying, collecting and organizing information related to the environmental impacts of the project. Applying different assessment methods to various goals such as ensuring the application of all environmental factors associated with the project, the adequacy and the ability to select a selection method to determine the options and definitions of deficiencies, adequacy and proportionality for the provision of information and results, and all-rounded and the credit is sufficient. Evaluation methods with regard to the wide range of information required, different parameters are chosen for analysis. Some of these parameters include the range of effect, severity or magnitude of the effect, the definite or probable effect, the durability of the effect and the reversibility of the effect that the choice of two or more factors is considered for the analysis of the effects. In general, some of the methods The following is used to evaluate the effects [2]:

Checklist method: Evaluation without any size of their approximate volume, Matrix method: Quantitative evaluation of effects, taking into account the activity column and the effects column, Network Analysis: Secondary and Third-Grade Impact Assessments, Mapping: Generating different layers of information as map and overlapping them, Modeling of pollutant emissions: Using environmental models to determine the distribution of pollutants and identify vulnerable areas. Although evaluation methods are diverse, some of the indicators and parameters should be taken into account in all evaluation studies. The outline of some of the main pillars of an in-depth evaluation study is as follows: A technical description of a project that involves microprojects in the construction, operation, and disposal phases of a project. Determining the scope of studies that, given the extent of the project's impact on the environment, Identify the physical, chemical, biological, socio-cultural, socioeconomic environments that at least include the following: physical and chemical environment including topography, soil, geology, surface water and underground waters, air, sound And climate, the biological environment including vegetation and animal, the list of plant and animal species at risk, Presence of protected areas relative to the project, habitat status, socioeconomic-cultural environment, including all relevant parameters such as traditions, religion, population, number of households, income, employment, and ancient and cultural influences, the study of the negative and positive effects on Environment, analysis of positive and negative impacts on the environment according to the selected method of evaluation, strategies for reducing the negative effects of the project on the environment, the project management and environmental monitoring project [4]. According to the checklist proposed by the Environmental Protection Agency of Iran, plans and projects that were eligible for environmental assessment studies in the API and Suran County were extracted by scale determination. To prioritize them, the Delphi method (Figure 1), which is a constructive communication technique or method, is used to predict interactivity based on the resilience of the experts. This approach used in futures studies mainly targets such as discovering innovative and reliable ideas or preparing the right information for decision making. The Delphi method is a structured process for collecting and categorizing knowledge in a group of experts and experts, through distributed questionnaires among these individuals, and feedback from controlled responses and comments received. The validity of the Delphi method is not the number of participants in the research, which depends on the scientific reputation of the participating specialist. The participants in the Delphi research include 5 to 20 people. The minimum number of participants depends on how the research methodology is designed. Publish this information without the identity of the providers. The main elements in Delphi's early methods are: Structuring the flow of information, providing feedback to participants, and uncovering the identity of the participants $[12,13]$.

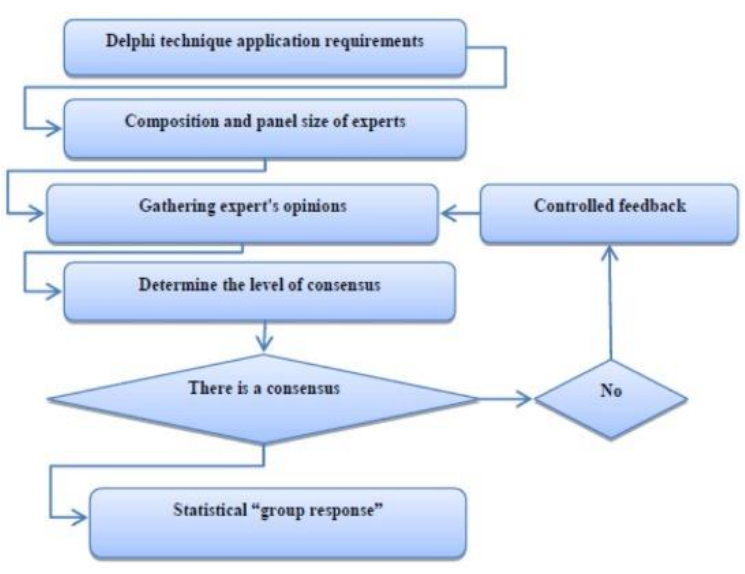

Figure 1: The Theoretical Framework of the Delphi Method in Qualitative Research

\section{RESULTS AND DISCUSSION}

\subsection{Industrial area}

In the northeast of the city of Suran and on the aquifer of the Suran plain and in the upstream of the agricultural lands of Chah Azim Village (Figure 2 ), it has an area of 2 hectares and is mainly active in the service industries affiliated with the building industry and storage storage facilities of the fruit. Investigations show that these types of industrial and service units do not have the potential for contamination due to the type and scale of activity.

Considering the primary goals of the settlements in order to improve the environmental, social and economic conditions of the area, it is better for the relevant organizations to train all different people involved in settlements and to comply with environmental standards and standards and continuous monitoring to prevent harvesting. Unauthorized use of groundwater resources and adverse impacts on downstream drinking water and downstream agricultural wells, the establishment of a wastewater treatment network for existing industries in addition to the objective of economic profitability through contamination reduction, will contribute to national costs [4].

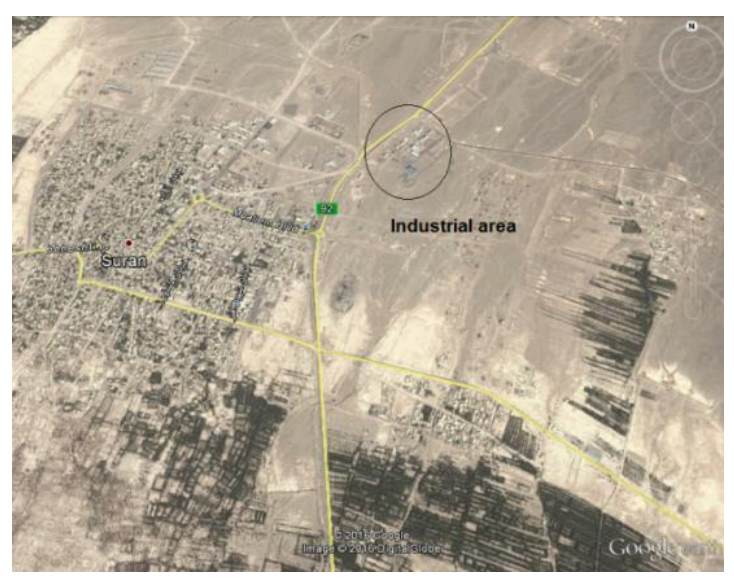

Figure 2: Souran Industrial Zone

\subsection{Cement factory}

In the north of the city of Suran and on the branches of the seasonal river of Apatan and upstream of Ghannat Apatan and Marugok in the study stage (Figure 3). Since today, the establishment of cement factories that utilizes large investments is usually accompanied by job creation and other economic aspects. But in line with these economic benefits, the environmental damage caused by cement factories is inevitable. These injuries include air pollution and water resources and degradation of vegetation. Some of the contributing factors are: [10]: Redundancy due to the process of milling raw materials, gases such as nitrogen dioxide and sulfur dioxide that combustion of fuels such as oil and coal for the furnace furnace the heavy elements contained in calcareous materials that are 
released into the furnace gases, organic materials and toxic metals from the burning of organic waste garbage in the raw materials. In order to provide economic and environmental justifications for the cement industry, a strong mix of appropriate environmental pollution prevention strategies and economically justifiable activities are needed.

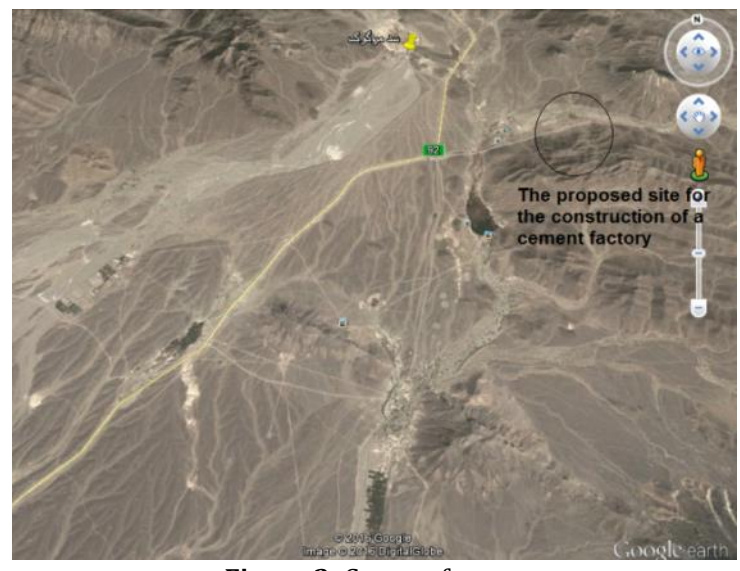

Figure 3: Cement factory

\subsection{Reservoir dam and water pipeline}

With a capacity of 67 million cubic meters, aimed at preventing destructive floods and providing 4 million cubic meters of drinking water annually, the Mashkid River was built (Figure 4). In addition to supplying drinking water in Zaboli, Suran, Hidooch and lower villages, this dam will prevent surface waters from leaving the border. Mashhad Dam is a type of earth with a clay core of 1472 meters in height, a crown width of 8 meters and a dam height of 24 meters in the river bed, and the surface of the lake is over 1801 hectares. The length of the water pipeline from Mashikid olya dam to the city of Suran is $58 \mathrm{~km}$, to the city of Mordan $4 \mathrm{~km}$ and to the city of Hydoch is $26.5 \mathrm{~km}$. The effects of damping on the fauna and flora of the area for dry areas should be investigated. So that accumulation of pollutants behind the dams and their stagnation increases the pollution of soil and water, which leads to the outbreak of diseases in humans and other living organisms [14]. Changes in the quality of water behind dams, including temperature, nutrients, dissolved gases, as well as climate change (humidity, temperature), cause biodiversity in the area to be monitored continuously [12].

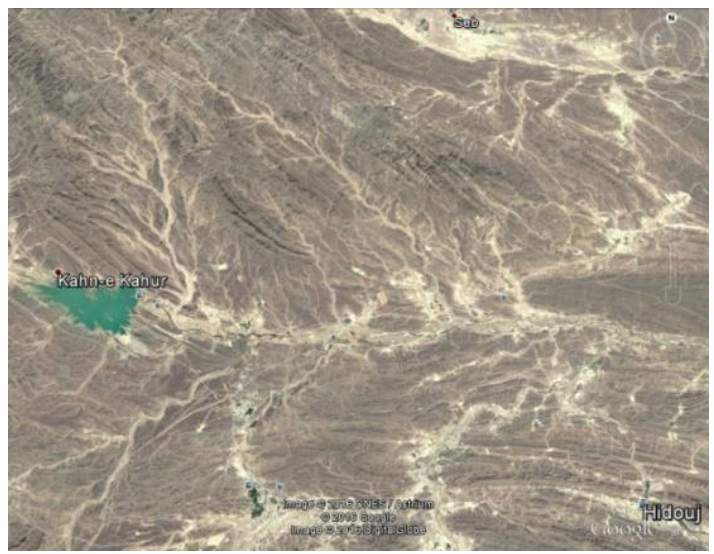

Figure 4: Mashkid Alia reservoir dam

\subsection{Landfill Center}

The problem of groundwater contamination due to penetration of leachate is the major problem of landfill dumps due to non-observance of the exact engineering principles. In these places, surface waters gradually dissolve some garbage and mix with leachate of garbage and form a highly polluting liquid. One of the products of waste fermentation is methane gas and carbon dioxide gas. The amount of gas produced directly relates to moisture, temperature and composition of waste. The amount of gas produced is about 2 liters per 1 kilogram of dry garbage, which runs horizontally across the earth from 5 to 24 centimeters vertically and 7.5 to 42.5 centimeters a day. [15]. Carbon dioxide increases the hardness of groundwater and also increases the water content due to lower acidity and corrosion.

The sewage disposal and disposal center in the city of Suran is located in the south of the village of KantiDar (Figure 5). So that waste is deposited in the pit and buried. Due to its location in the vicinity of the aquifer and the slope of the area towards the branches of the river Rotak, there is a risk of leakage and pollution of water and soil.

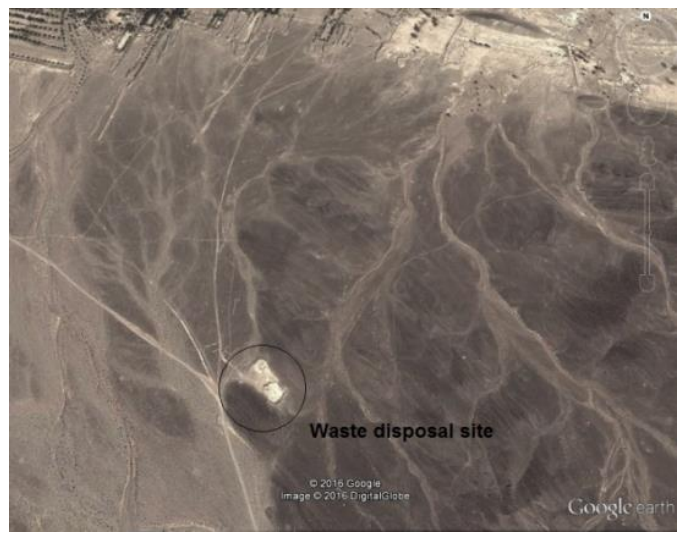

Figure 5: Landfill Center

\subsection{Oil and gas terminal}

Car fuel is a major source of air pollutants. Photochemical smog is also the result of the interactions of various types of pollutants entering the air from fuel, especially gasoline-powered cars. Solar radiation also triggers a photochemical reaction that occurs between pollutants emitted from the car's exhaust pipe and is the source of smoke oxidation production [16]. According to the pollutants from gasoline consumption, including two steps, one Leakage refueling time: For every 3 to 4 minutes, 40-50 cc refueling and evaporation for every 3 to 4 minutes, $30-40 \mathrm{cc}$, and the other after gasoline fuels [7]. Pollutants produced from the site include nitrogen oxides, carbon oxides, hydrocarbons, anhydride sulfides, aldehydes, organic acids, benzopyrins and suspended particles. At each station of the gas station, the amount of pollutants produced in grams per day should be calculated as Accurately measured.

Two gasoline and gasoline terminals are active in the city of Suran (Figure 6). In addition, due to these sales terminals, on the aquifers of the Souran plain and the Hydow plain, there is a potential for leakage and pollution of water and soil.

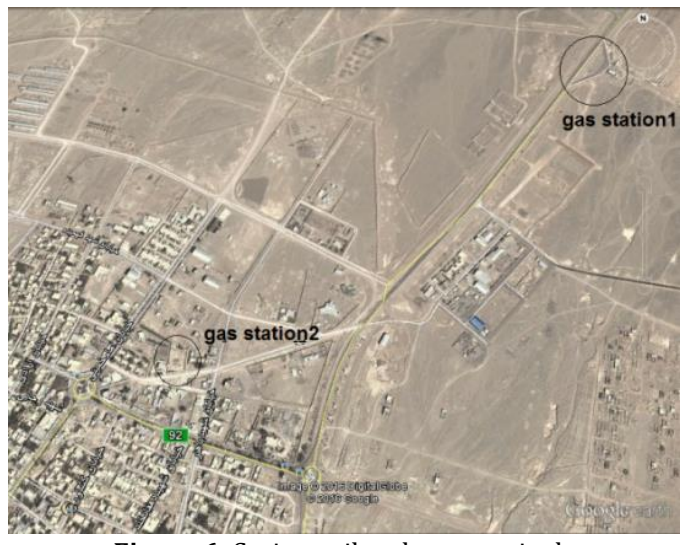

Figure 6: Syringe oil and gas terminals

\subsection{Brick Furnace Complex}

The Brick Cooking Complex in the furnace in the village of Keki and Rigjehi, north of the city of Suran shown in Figure 7 , has actual effects on the environment. Considering the type of furnace (tunnel) and the type of fuel consumed by the factory (fuel oil), emissions include emissions of fluorine from non-metallic clay minerals and nitrogen oxide and sulfur from oil and coal in the furnace smoke output Should be considered. Field studies in the region indicate that the baking cooking complex in the furnace in the village of Kaki and Reggae has actual effects on the environment. On the other hand, due to the type of raw material of the factory where the clay and sometimes the content of lime content is high, the appearance of acidic, corrosive and toxic compounds caused by soil sulfur compounds inevitable and its obvious effects on the structure of the furnace and its hidden effects on the health of the labor force. Study and study. Control of particles smaller than 10 microns from soil milling, guidance and conditioning of gases during exiting and at high levels of management, using some methods to control corrosive gases is recommended [17]. 


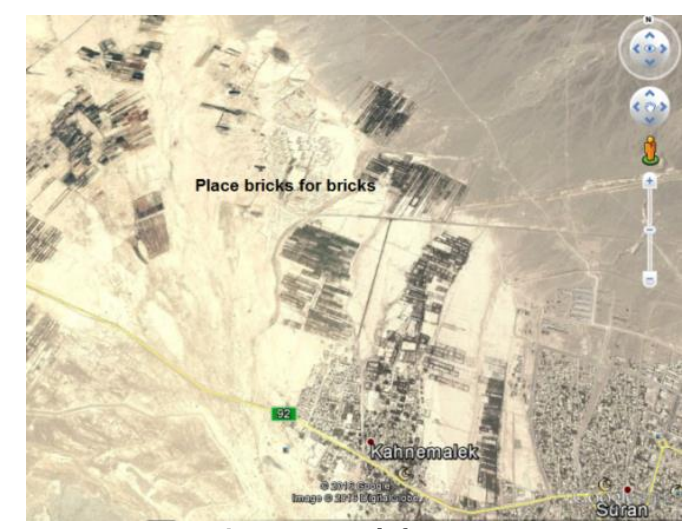

Figure 7: Brick furnaces

Reduction in clay storage and inventory due to uncontrolled operation leads to the fall of the dead bed and the gradual increase in the area of harvesting through the clearing and excavation, causing excessive deviation of the waterway and, as a result of dynamic changes, over time. In the case of the exploitation of clay mines in the site of excavation, the slowing of the flow of water, along with low recharge, has increased the number of mineral particles and organic matter deposited [9, 14].

\section{CONCLUSION}

We found brick baking kilns have obvious and hidden effects on biological health and are considered as a major threat to the ecosystem of the region. Considering that they are located in the upstream of agricultural lands and some drinking water wells, and the direction of the prevailing wind from north to south and the general slope of the earth from the northwest to the south east, the analysis of environmental problems as well as all preventive measures and effects Section is suggested.

Considering that in the present situation it is not necessary to start environmental assessment studies before the construction of the projects is started, and on this basis, the employers begin their development projects and perform evaluation studies during the operation. In some cases, studies are carried out at the end of the construction phase. For this purpose, it is recommended that the current environmental assessment of the environmental impacts be promoted to its favorable and appropriate position as proposed in Figure 7.

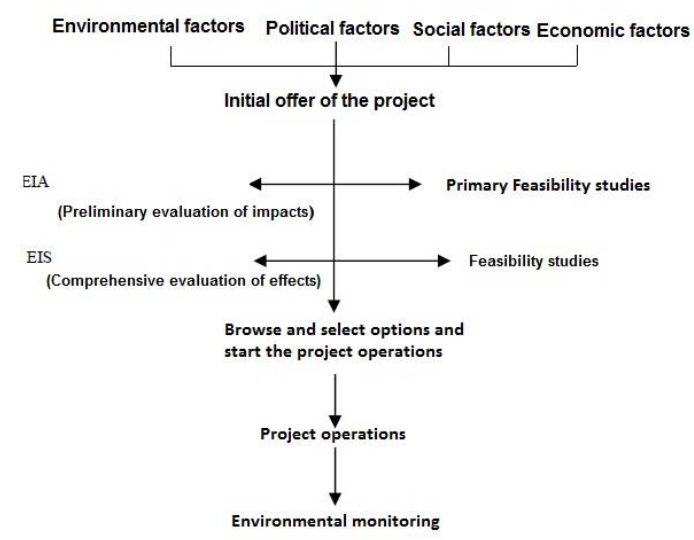

Figure 7: Status of the proposed status of the environmental monitoring program

\section{REFERENCES}

[1] Alphan, H. 2016. Analysis of landscape changes as an indicator for environmental monitoring. Environmental Monitoring and Assessment, 189, 24. DOI: 10.1007 / s10661-016-5748-7.

[2] Guidelines for environmental monitoring and monitoring of plans and projects. 2015. First ed., Department of Environment, Islamic Republic of Iran.

[3] Environmental Impact Assessment of Construction Plans. 2008. Ninth Edition, Department of Environment, Islamic Republic of Iran.

[4] Yaacof, N., Qamaruzzaman, N., Yusup, Y. 2017. Comparison of the Method of Odor Impact Evaluation Using Calpuff Dispersion Modeling and On-Site Odor Monitoring. Engineering Heritage Journal, 1, 1-5.

[5] Ghazban, F. 2014. Environmental Geology, Second ed., University of Tehran, Iran.

[6] Jabbour, J., Flachsland, C. 2017. 40 years of global environmental assessments: A retrospective analysis. Environmental Science and Policy, 77, 193-202. doi.org/10.1016/j.envsci.2017.05.001

[7] Namdar, Z., Rezaeian, S., Jafarzadeh, N. 2012. Environmental impact analysis of brickhouse furnaces in Mohammad Abad Ghahab region, Isfahan, The First International Conference on Environmental Crises and Ways to Improve, Iran. https: //www.civilica .com / Paper-ICECS01ICECS01_335.html

[8] Abad, S.M.S., AbulAbas, A., Azizi, F., DstyarPur, S., and Ovens, B. 2013. Environmental Impact Case Study, Bojnord East Building, conference, industrial burners and furnaces, Iran.

[9] Hesampour, M., Nozari, A., Jorfi, S., Lotfi, Y. 2006. Pollution from petrol stations in avaz, the ninth national conference on environmental health, Iran.

[10] Sotuhiyan, F., Tavakoli, B., Ranjbaran, M. 2015. Environmental Impact Assessment, Selected Indiscriminate Sand Waste JubenGilan, The international conference on science, Engineering and Technology Environment, Iran. https://www.civilica.com/ Paper-CESET01CESET01_370.html

[11] Abbasi, J., Salari, M. 2006. Environmental pollution cement, Mining engineering students conference, Iran.

[12] Iranian State Information Portal, Sistan and Baluchestan Province, 2016. http://www.sbportal.ir/fa/cities/sibsoran

[13] AbulHasani, N., Sayadi, M. H. 2011. Sealants and ways to reduce its negative environmental effects, The first national conference on development, Iran.

[14] Mirzaaghabeik, H., Vosoughifar, H. R. 2015. Comparison between the quality and quantity of seismic damage index for LSF systems. Engineering Science and Technology, 19,497-510. doi: 10.1016 / j. jestch.2015.08.013

[15] Ando. 2014. Field development optimization with environmental considerations in the Canadian shale gas project. Journal of the Japanese Association for Petroleum Technology, 79, 434-440. DOI: 10.3720 / japt.79.434

[16] Haas, P. M. 2017. The Epistemic Authority of the Decision-Oriented Global Environmental Assessments, Environmental Science and Policy 76. doi.org/10.1016/j.envsci.2017.03.013 